\title{
EDITORIAL
}

\section{Looking back at genomic medicine in 2011}

\author{
Charles Auffray ${ }^{* 1,1}$, Timothy Caulfield ${ }^{2 \dagger}$, Muin J Khoury ${ }^{3 \dagger}$, James R Lupski ${ }^{4,5 \dagger}$, Matthias Schwab ${ }^{6,7 \dagger}$ and Timothy Veenstra ${ }^{8 \dagger}$
}

Genomic medicine, in its broadest sense of being medical developments informed by 'omic' advances, has continued to move towards the clinic in 2011. To mark the end of the year and the beginning of 2012, the editors of the six sections within Genome Medicine were invited to provide their highlights of the past year and to hint at the developments that we are likely to see in the near future.

Six different areas of progress are covered here, but the core of genomic medicine continues to be intrinsically linked to improvements in the underlying technology, and two obvious examples are sequencing and mass spectrometry. Technological advances have enabled larger studies and more complex analyses, allowing researchers and clinicians to track changes within a single cell and yet spot patterns across a whole population and within an entire physiological system. The foundations laid in 2011 should help the field to tackle the challenges of translating genomic medicine to the clinic in 2012.

\section{Complex genomic rearrangements and disease}

The past year has been marked by advances in the speed, accuracy and scale of genome sequencing. These improvements have led to the first population-scale genome sequencing study to provide information on structural variants [1]. Over 15,000 novel structural variants were identified from 185 individuals. Analysis of breakpoint junctions revealed that $70 \%$ of deletions and almost $90 \%$ of insertions showed microhomology ranging from $2 \mathrm{bp}$ to $376 \mathrm{bp}$ at the junctions. This suggests that nonhomologous recombination mechanisms are predominant in copy number variation, and that microhomology-mediated DNA replication mechanisms, such as microhomologymediated break-induced replication, might have a major role in human genome structural variation.

Genome sequencing also revealed the extent of complex genomic rearrangements (CGRs) in disease. Over 700 genomes from different cancers were studied, and 'chromosome catastrophes' were identified in 2 to $3 \%$

\footnotetext{
tEqual contributors

*Corresponding author: auffray@vjf.cnrs.fr

${ }^{1}$ CNRS Institute of Biological Sciences, European Institute for Systems Biology \&

Medicine, Claude Bernard University, 69007 Lyon, France

Full list of author information is available at the end of the article
}

of all cancers and in up to $25 \%$ of bone cancers [2]. This phenomenon, also termed 'chromothripsis' (shattering and regluing of chromosomes), is primarily localized to single chromosomes, but includes multiple structural genomic changes, such as gains, losses and inversions. As a result, chromothripsis can lead to the simultaneous occurrence of mutations in a number of different cancercausing genes. Cancer is known to be driven by somatically acquired point mutations and chromosomal rearrangements, conventionally thought to accumulate gradually over time. However, chromothripsis is a one-off event resulting in multigenic changes [2]. It remains to be shown whether chromothripsis is a major driver of cancer.

Intriguingly, a similar chromosome catastrophe event that resulted in CGRs was found to be associated with a small fraction of genomic disorders [3]. This involved a germline or constitutional rearrangement event early in embryogenesis rather than somatically acquired mutations and seemed to occur via a DNA-replication-based mechanism. Triplicated genomic segments were also identified within the rearrangements, and microhomology was present at many of the breakpoint junctions. The triplication cannot readily be explained by chromothripsis, as it requires a gain of genetic information, probably resulting from DNA replication. Other CGRs identified in association with genomic disorders included triplications; triplicated dosage-sensitive genes conveyed a more severe clinical phenotype than duplication. Triplications seem to occur by a double crossover event within a flanking low-copy repeat and are tandem in nature, similar to earlier predictions from an unequal crossingover or non-allelic homologous recombination (NAHR) model [4]. However, many of the observed triplications have a complex 'duplication-inverted triplication-duplication' structure, which requires only two breakpoint junctions. One of these is generated by an initial NAHR event between inverted repeats, and the other occurs by a nonhomologous mechanism, potentially a DNA replicationbased mechanism that results in microhomology at the breakpoint junction [5]. The inversion allows distant genomic regions to be brought into spatial proximity.

A summary of 2011 would not be complete without highlighting exome sequencing and its role in the elucidation of the gene(s) responsible for a number of 
different Mendelian disorders [6]. Genomic studies have so far revealed the tremendous extent of rare variants in individual genomes. This has led to the concept of 'clan genomics' [7], wherein the most relevant medically actionable variation may be rare variants that occurred as novel combinations or as new mutations in your personal genome or that of your nearest relatives.

James R Lupski, Section Editor, Molecular genetics, genomics $\mathcal{E}$ epigenetics of disease

\section{Bringing quantification to the proteome}

The ability to conduct global analysis of proteomes has existed for about a decade now. During this period most of the progress has been on increasing the number of proteins identified within the proteome. Because of the lack of inherent quantification within the data supplied by high-throughput mass spectrometry (MS), measuring the absolute concentration of proteins across the proteome has lagged behind. This situation is analogous to having a recipe in which the ingredients are listed but the amount of each required is not supplied. Without knowing how much of each ingredient to add, it is unlikely that the dish would taste very good.

Recent studies have moved to develop techniques to supply this vital piece of information. Selbach and colleagues [8] used a combination of stable isotope incorporation and MS to quantify pulse-labeled proteins and 4-thiouridine incorporation to quantify newly synthesized RNA in mouse cells. These results showed that genes that respond quickly to stimuli (such as those encoding transcription factors and signaling proteins) have short protein and mRNA half lives. Constitutive processes (such as translation and central metabolism) were populated by genes giving rise to stable proteins and mRNA. A more recent study by Aebersold and colleagues [9] provided an absolute quantitative estimate of approximately 7,000 proteins in a human cell line during exponential and $\mathrm{M}$ phase growth. This study also found that proteins related to translation were found in high abundance, whereas those involved in processes such as transcription and signaling are present in very low abundance. These results are in agreement with those found by Selbach and colleagues [8], with both studies suggesting that the correlation between mRNA and protein levels is greater than previously reported $[10,11]$.

Although it is possible to measure the absolute number of specific proteins within complex mixtures [12], these studies represent a new, hopefully broader, effort in determining the absolute abundances of proteins across an entire proteome. Frankly, without this quantitative information it is impossible to accurately understand cellular processes at a systems-level view.

Timothy Veenstra, Section Editor, Post-genomic advances in medicine

\section{The human microbiome, our personal health and diseases}

Microbial cells in the human body outnumber human cells by two orders of magnitude. During the past decade, there has been growing interest in the analysis of these microbial communities, which are an integral part of the human body and provide us with nutrients essential to our health. With the rapid increase in sequencing power, the characterization of the so-called 'microbiome' has given rise to large 'metagenomic' datasets, revealing a wealth of microbial species that were previously unknown and cannot be cultured.

The gut microbiome is the most extensively studied part of the human microbiome so far, and this past year the international MetaHIT Consortium has consolidated the data to support the existence of a limited number of 'enterotypes', stable clusters of bacterial communities that are common to groups of individuals belonging to different human populations rather than specific for each population $[13,14]$. Enterotypes are 'well-balanced hostmicrobial symbiotic states that might respond differently to diet and drug intake' and warrant functional analysis to complement species identification obtained through next-generation sequencing.

The same sequencing approach is being successfully extended to characterize the microbiome in other human tissues, such as nasal passages, oral cavities, skin and urogenital tract within the Human Microbiome Project $[15,16]$. Significant challenges remain in establishing robust and efficient bioinformatics pipelines to deal with the very large sequence datasets generated [17], but the integration of metagenomics with functional genomics has started to provide new insights into the role of the microbiome in health and in disease susceptibility, diagnosis, progression and treatment, as reviewed extensively by Nicholson and colleagues in this journal [18]. Although emphasis so far has been on bacterial communities, metagenomics provide simultaneous access to fungi, protozoa and viruses, revealing that the vast majority had not been identified through classical culture-based techniques. Functional metagenomics is thus opening a window into an as-yet largely unexplored biological world, and is starting to fill gaps in our knowledge of health and diseases. It is likely that microbiome studies will flourish in the coming years and will contribute to a more personal appraisal of our medical condition and potential response to treatment.

Charles Auffray, Section Editor, Systems medicine and informatics

\section{Progress in pharmacogenomics and individualized medicine}

In the past year some very important contributions have been made indicating that genomic information predicts 
drug response and adverse drug reactions, thereby promoting the concept of personalized medicine and pharmacogenomics. Although the integration of individualized medicine into clinical decision making is still limited [19], there is increasing evidence for genetic markers for major drug-induced hypersensitivity reactions in the major histocompatibility complex (MHC) region. Examples of such adverse reactions include the Steven-Johnson syndrome (SJS) and the related toxic epidermal necrolysis (TEN), with mortalities of $10 \%$ and $30 \%$, respectively.

Carbamazepine, an antiepileptic drug also used for treatment of other conditions, including bipolar disorders, and for pain management in trigeminal neuralgia, induces different manifestations of these hypersensitivity reactions. In 2004 the HLA-B*1502 allele was strongly associated with SJS/TEN in Han Chinese people [20]. In a recent study, 4,855 Taiwanese were prospectively screened for the HLA-B* 1502 allele before onset of carbamazepine treatment, and all HLAB*1502-positive people (7.7\%) were offered alternative medications to carbamazepine and did not develop SJS/ TEN [21]. Although the estimated historical incidence for SJS/TEN in Southeast Asians is $0.23 \%$, no cases of SJS/TEN were identified among the 4,120 study participants treated with carbamazepine. This prospective study clearly indicates that genetic testing for HLAB*1502 seems to be warranted in clinical practice for the prevention of carbamazepine-associated SJS/TEN in Southeast Asians.

Recent data have suggested that different HLA alleles might contribute to carbamazepine-related hypersensitivity reactions in patients with other ethnic backgrounds [22], and a genome-wide association study (GWAS) found a strong association for the HLA-A*3101 allele in 22 people with Northern European ancestry and carbamazepine-induced hypersensitivity reactions, as compared with 2,691 healthy controls [23]. Whereas the HLAB*1502 allele seems to be a phenotype-specific predictor for the development of SJS/TEN in Asians, in Europeans the HLA-A*3101 allele seems to be associated with multiple phenotypes of carbamazepine hypersensitivity reactions, including SJS/TEN. In a separate GWAS, multiple HLA class I and II alleles were identified as susceptibility factors for idiosyncratic amoxicillinclavulanate-induced liver injury, further supporting the importance of genetic variation in the MHC region in idiosyncratic adverse drug reactions [24].

In addition to the major efforts to individualize drug therapy using genomic information alone, metabolomics promises significant achievements towards a better understanding of the potential relevance of genetic variants in disease susceptibility as well as drug therapy, by the study of metabolism at the global level. A highlight in this field was the first analysis that comprehensively combined genomic information (from GWAS) with nontargeted metabolic profiling of serum from subjects of two independent cohorts $(\mathrm{n}=2,820)$ for hypothesis generation [25]. Meta-analysis revealed 37 independent loci with genome-wide significance, providing not only new functional insights for disease susceptibility but also novel biochemical data for genotype-dependent reactions to drug therapy. This approach highlights the enormous potential of integrated analyses for pharmacology and clinical pharmacology in the near future.

Matthias Schwab, Section Editor, Personalized medicine $\mathcal{E}$ therapeutics

\section{Beyond base pairs to bedside}

In February 2011, more than 10 years after a draft sequence of the human genome was published, the US National Human Genome Research Institute announced its new strategic plan for genomic medicine from base pairs to bedside [26]. The plan calls for evaluating the structure and biology of genomes; understanding the biology of disease; advancing the science of medicine; and improving the effectiveness of healthcare. Nevertheless, fulfilling the promise of genomics in improving health requires a multidisciplinary research agenda beyond bench to bedside, an agenda that will demonstrate added value of genome-based information for improving health in populations [27].

Currently, this translational research agenda is much less robust than discovery research, accounting for less than $2 \%$ of funded genomics research and research publications [28], but this is likely to change in the next decade as more and more applications make it to the bedside. Ongoing horizon scanning for genomic tests has revealed more than 330 genomic tests have reached the bedside since 2009 [29]. In addition, the US Food and Drug Administration has provided drug labeling information about adverse reactions for more than 80 gene-drug pairs [30].

With rapid improvements in technologies, we are seeing the leading edge of the applications of whole genome sequencing (WGS) in practice primarily in the identification of rare heritable conditions [31]. Deploying WGS in practice will require a systematic evidence-based approach to binning genes and gene variants into tiers based on levels of evidence for improving health; recently, Berg et al. [32] proposed a three-tier binning schema for WGS, based on the availability of information on their clinical validity and utility. The ultimate success of genomics for improving health will require adoption of evidence-based approaches for their use in clinical and public health practice.

Muin Khoury, Section Editor, Genomic epidemiology E public health genomics 


\section{Direct-to-consumer testing}

As genomic technologies advance at an accelerating pace, direct-to-consumer (DTC) genetic testing has emerged as a dominant area of ELSI (ethical, legal and social issues) inquiry. Indeed, over the past few years, DTC testing has received a tremendous amount of attention from policymakers, ELSI scholars and the popular press [33]. Although it remains uncertain whether this industry, which is fueled by the availability of cheap and efficient testing technologies, will attract a broad consumer base [34], its growth has triggered a diverse array of regulatory responses, from outright bans [35] to recommendations that call for the provision of accurate information and valid results [36].

The DTC industry has also allowed ELSI researchers to explore popular culture representations of genetics [37], how individuals react to genetic risk information and the motivations behind the use of DTC services [38]. Much of this research has provided surprising results highlighting both problems (for example, the degree to which the benefits and limitations of testing are often misrepresented [39] and the reality that much provided risk information may be inaccurate [40]) and the fact that some concerns may not be as problematic as previously thought (for example, the degree to which people become anxious after receiving predisposition information [41]). Given the appearance of the DTC industry, ELSI researchers are now contemplating future policy challenges. For example, the use of DTC services for the testing of children and the availability of cheap WGS, which is inevitable in the near future, seem likely to add new and challenging dimensions to the DTC story.

Timothy Caulfield, Section Editor, Social, ethical \& legal issues in genomic medicine

\section{Abbreviations}

CGR, complex genomic rearrangement; DTC, direct-to-consumer; ELSI, ethical, legal and social issues; GWAS, genome-wide association study; MHC, major histocompatibility complex; MS, mass spectrometry; NAHR, non-allelic homologous recombination; SJS, Steven-Johnson syndrome; TEN, toxic epidermal necrolysis; WGS, whole genome sequencing.

\section{Competing interests}

$J R L$ is a consultant for Athena Diagnostics, has stock ownership in 23andMe and Ion Torrent Systems, and is a co-inventor on multiple United States and European patents for DNA diagnostics. The Department of Molecular and Human Genetics at Baylor College of Medicine derives revenue from clinical testing by high-resolution human genome analyses. All other authors declare that they have no competing interests.

\section{Author details}

${ }^{1}$ CNRS Institute of Biological Sciences, European Institute for Systems Biology \& Medicine, Claude Bernard University, 69007 Lyon, France. ²Faculty of Law and School of Public Health, 461 Law Centre, University of Alberta, Edmonton, T6G 2H5, Canada. ${ }^{3}$ Office of Public Health Genomics, Centers for Disease Control and Prevention, 1600 Clifton Rd, NE, MS E61, Atlanta, GA 30333, USA. ${ }^{4}$ Departments of Molecular and Human Genetics and Pediatrics, Baylor College of Medicine, Houston, TX 77030, USA. ${ }^{5}$ Texas Children's Hospital, Houston, TX 77030, USA. ${ }^{6}$ Dr Margarete Fischer-Bosch Institute of Clinical Pharmacology, Auerbach Str. 112, 70367 Stuttgart, Germany. ${ }^{7}$ Department of
Clinical Pharmacology, Institute of Experimental and Clinical Pharmacology and Toxicology, University Hospital, 72076 Tübingen, Germany. ${ }^{8}$ Laboratory of Proteomics and Analytical Technologies, National Cancer Institute at Frederick, Frederick, MD 21702-1201, USA

Published: 30 January 2012

\section{References}

1. Mills RE, Walter K, Stewart C, Handsaker RE, Chen K, Alkan C, Abyzov A, Yoon SC, Ye K, Cheetham RK, Chinwalla A, Conrad DF, Fu Y, Grubert F, Hajirasouliha I, Hormozdiari F, lakoucheva LM, labal Z, Kang S, Kidd JM, Konkel MK, Korn J, Khurana E, Kural D, Lam HY, Leng J, Li R, Li Y, Lin CY, Luo R, et al.: Mapping copy number variation by population-scale genome sequencing. Nature 2011, 470:59-65

2. Stephens PJ, Greenman CD, Fu B, Yang F, Bignell GR, Mudie L, Pleasance ED, Lau KW, Beare D, Stebbings LA, McLaren S, Lin ML, McBride DJ, Varela I, NikZainal S, Leroy C, Jia M, Menzies A, Butler AP, Teague JW, Quail MA, Burton J, Swerdlow H, Carter NP, Morsberger LA, lacobuzio-Donahue C, Follows GA, Green AR, Flanagan AM, Stratton MR, et al:: Massive genomic rearrangement acquired in a single catastrophic event during cancer development. Cell 2011, 144:27-40.

3. Liu P, Erez A, Nagamani SC, Dhar SU, Kołodziejska KE, Dharmadhikari AV, Cooper ML, Wiszniewska J, Zhang F, Withers MA, Bacino CA, CamposAcevedo LD, Delgado MR, Freedenberg D, Garnica A, Grebe TA, HernándezAlmaguer D, Immken L, Lalani SR, McLean SD, Northrup H, Scaglia F, Strathearn L, Trapane P, Kang SH, Patel A, Cheung SW, Hastings PJ, Stankiewicz $P$, Lupski JR, et al:: Chromosome catastrophes involve replication mechanisms generating complex genomic rearrangements. Cell 2011, 146:889-903.

4. Liu P, Erez A, Nagamani SC, Bi W, Carvalho CM, Simmons AD, Wiszniewska J, Fang P, Eng PA, Cooper ML, Sutton VR, Roeder ER, Bodensteiner JB, Delgado MR, Prakash SK, Belmont JW, Stankiewicz P, Berg JS, Shinawi M, Patel A, Cheung SW, Lupski JR: Copy number gain at Xp22.31 includes complex duplication rearrangements and recurrent triplications. Hum Mol Genet 2011, 20:1975-1988.

5. Carvalho CM, Ramocki MB, Pehlivan D, Franco LM, Gonzaga-Jauregui C, Fang P, McCall A, Pivnick EK, Hines-Dowell S, Seaver LH, Friehling L, Lee S, Smith R, Del Gaudio D, Withers M, Liu P, Cheung SW, Belmont JW, Zoghbi HY, Hastings PJ, Lupski JR: Inverted genomic segments and complex triplication rearrangements are mediated by inverted repeats in the human genome. Nat Genet 2011, 43:1074-1081.

6. Gonzaga-Jauregui C, Lupski JR, Gibb RA: Human genome sequencing in health and disease. Annu Rev Med 2012, 63:35-61.

7. Lupski JR, Belmont JW, Boerwinkle E, Gibbs RA: Clan genomics and the complex architecture of human disease. Cell 2011, 147:32-43.

8. Schwanhäusser B, Busse D, Li N, Dittmar G, Schuchhardt J, Wolf J, Chen W, Selbach M: Global quantification of mammalian gene expression control. Nature 2011, 473:337-342.

9. Beck M, Schmidt A, Malmstroem J, Claassen M, Ori A, Szymborska A, Herzog F, Rinner O, Ellenberg J, Aebersold R: The quantitative proteome of a human cell. Mol Syst Biol 2011, 7:549-556.

10. de Sousa Abreu R, Penalva LO, Marcotte EM, Vogel C: Global signatures of protein and mRNA expression levels. Mol Biosyst 2009, 5:1512-1526.

11. Maier T, Guell M, Serrano L: Correlation of mRNA and protein in complex biological samples. FEBS Lett 2009, 583:3966-3973.

12. Lame $M E$, Chambers EE, Blatnik M: Quantitation of amyloid beta peptides $A \beta(1-38), A \beta(1-40)$, and $A \beta(1-42)$ in human cerebrospinal fluid by ultraperformance liquid chromatography-tandem mass spectrometry. Anal Biochem 2011, 419:133-913.

13. Arumugam M, Raes J, Pelletier E, Le Paslier D, Yamada T, Mende DR, Fernandes GR, Tap J, Bruls T, Batto JM, Bertalan M, Borruel N, Casellas F, Fernandez L, Gautier L, Hansen T, Hattori M, Hayashi T, Kleerebezem M, Kurokawa K, Leclerc M, Levenez F, Manichanh C, Nielsen HB, Nielsen T, Pons N, Poulain J, Qin J, Sicheritz-Ponten T, Tims S, et al:: Enterotypes of the human gut microbiome. Nature 2011, 473:174-180

14. MetaHit Consortium [http://www.metahit.eu/]

15. Lewis CM Jr, Obregon-Tito A, Tito RY, Foster MW, Spicer PG: The Human Microbiome Project: lessons from human genomics. Trends Microbio/ 2012, 20:1-4.

16. Human Microbiome Project [http://commonfund.nih.gov/Hmp/]

17. Solovyev $\mathrm{V}$, Tatarinova TV: Towards the integration of genomics, 
epidemiological and clinical data. Genome Med 2011, 3:48.

18. Kinross JM, Darzi AW, Jeremy K Nicholson JK: Gut microbiome-host interactions in health and disease. Genome Med 2011, 3:14.

19. Schwab M, Schaeffeler E. Warfarin pharmacogenetics meets clinical use. Blood 2011, 118:2938-2939.

20. Chung WH, Hung SI, Hong HS, Hsih MS, Yang LC, Ho HC, Wu JY, Chen YT: Medical genetics: a marker for Stevens-Johnson syndrome. Nature 2004, 428:486.

21. Chen P, Lin JJ, Lu CS, Ong CT, Hsieh PF, Yang CC, Tai CT, Wu SL, Lu CH, Hsu YC, Yu HY, Ro LS, Lu CT, Chu CC, Tsai JJ, Su YH, Lan SH, Sung SF, Lin SY, Chuang HP, Huang LC, Chen YJ, Tsai PJ, Liao HT, Lin YH, Chen CH, Chung WH, Hung SI, Wu $J Y$, Chang CF, Chen L, Chen YT, Shen CY: Carbamazepine-induced toxic effects and HLA-B*1502 screening in Taiwan. N Engl J Med 2011, 364:1126-1133.

22. Ozeki T, Mushiroda T, Yowang A, Takahashi A, Kubo M, Shirakata Y, Ikezawa Z, lijima M, Shiohara T, Hashimoto K, Kamatani N, Nakamura Y: Genome-wide association study identifies HLA-A*3101 allele as a genetic risk factor for carbamazepine-induced cutaneous adverse drug reactions in Japanese population. Hum Mol Genet 2011, 20:1034-1041.

23. McCormack M, Alfirevic A, Bourgeois S, Farrell JJ, Kasperavičiūté D, Carrington M, Sills GJ, Marson T, Jia X, de Bakker PI, Chinthapalli K, Molokhia M, Johnson MR, O'Connor GD, Chaila E, Alhusaini S, Shianna KV, Radtke RA, Heinzen EL, Walley N, Pandolfo M, Pichler W, Park BK, Depondt C, Sisodiya SM, Goldstein DB, Deloukas P, Delanty N, Cavalleri GL, Pirmohamed M: HLA-A*3101 and carbamazepine-induced hypersensitivity reactions in Europeans. $N$ Engl $f$ Med 2011, 364:1134-1143.

24. Lucena MI, Molokhia M, Shen Y, Urban TJ, Aithal GP, Andrade RJ, Day CP, RuizCabello F, Donaldson PT, Stephens C, Pirmohamed M, Romero-Gomez M, Navarro JM, Fontana RJ, Miller M, Groome M, Bondon-Guitton E, Conforti A, Stricker BH, Carvajal A, Ibanez L, Yue QY, Eichelbaum M, Floratos A, Pe'er I, Daly MJ, Goldstein DB, Dillon JF, Nelson MR, Watkins PB, Daly AK: Susceptibility to amoxicillin-clavulanate-induced liver injury is influenced by multiple HLA class I and II alleles. Gastroenterology 2011, 141:338-347.

25. Suhre K, Shin SY, Petersen AK, Mohney RP, Meredith D, Wägele B, Altmaier E, Deloukas P, Erdmann J, Grundberg E, Hammond CJ, de Angelis MH, Kastenmüller G, Köttgen A, Kronenberg F, Mangino M, Meisinger C, Meitinger T, Mewes HW, Milburn MV, Prehn C, Raffler J, Ried JS, Römisch-MargI W, Samani NJ, Small KS, Wichmann HE, Zhai G, Illig T, et al:. Human metabolic individuality in biomedical and pharmaceutical research. Nature 2011, 477:54-60.

26. Green ED, Guyer MS: Charting a course for genomic medicine: from base pairs to bedside. Nature 2011, 470:204-213.

27. Khoury MJ, Gwinn M, Bowen MS, Dotson WD: Beyond base pairs to bedside: a population perspective on how genomics can improve health. $\mathrm{Am} J$ Public Health 2011. doi: 10.2105/AJPH.2011.300299.
28. Schully SS, Benedicto CB, Gillanders EM, Wang SS, Khoury MJ: Translational research in cancer genetics: the road less travelled. Publ Health Genomics 2011, 14:1-8.

29. Gwinn M, Grossniklaus DA, Yu W, Melillo S, Wulf A, Flome J, Dotson WD, Khoury MJ: Horizon scanning for new genomic tests. Genet Med 2011, 13:161-165.

30. Food and Drug Administration: Table of pharmacogenomic biomarkers in drug labels [http://www.fda.gov/drugs/scienceresearch/researchareas/ pharmacogenetics/ucm083378.htm]

31. Manolio TA, Green ED: Genomics reaches the clinic: from basic discoveries to clinical impact. Cell 2011, 147:14-16.

32. Berg J, Khoury MJ, Evans JP: Deploying whole genome sequence in clinical practice and public health: meeting the challenge one bin at a time. Genet Med 2011, 13:498-504

33. Caulfield T, McGuire A: Direct-to-consumer genetic testing: perceptions, problems, and policy responses. Annu Rev Med 2012, 63:1.1-1.11

34. Wright CF, Gregory-Jones S: Size of the direct-to-consumer genomic testing market. Genet Med 2010, 12:594.

35. Wright C: Ban on DTC genetic tests in Germany. Population Health Genome Foundation, 28 April 2009. [http://www.phgfoundation.org/news/4562/]

36. American Bar Association: Resolution 114. ABA urges direct access to diagnostic medical testing, 2011. [http://www.abanow. org/2011/07/2011am114/]

37. Murray ABV, Carson MJ, Morris CA, Beckwith J: Illusions of scientific legitimacy: misrepresented science in the direct-to-consumer: misrepresenting science in the genetic-testing marketplace. Trends Genet 2010, 26:459-461.

38. SuY, Howard HC, Borry P: Users' motivations to purchase direct-toconsumer genome-wide testing: an exploratory study of personal stories. Community Genet 2011, 2:135-146

39. Einsiedel EF, Geransar R: Framing genetic risk: trust and credibility markers in online direct-to-consumer advertising for genetic testing. New Genet Soc 2009, 28:339-362.

40. Kuehn BM: Inconsistent results, inaccurate claims plague direct-toconsumer gene tests. JAMA 2010, 304:1313-1315.

41. Bloss CS, Schork NJ, Topol EJ: Effect of direct-to-consumer genome wide profiling to assess disease risk. N Engl J Med 2011, 364:524-534.

doi:10.1186/gm308

Cite this article as: Auffray $C$, et al.: Looking back at genomic medicine in 2011. Genome Medicine 2012, 4:9. 